\title{
PERUBAHAN JABATAN: DAMPAKNYA PADA KINERJA DAN KESEJAHTERAAN
}

\author{
Sukamtono $^{1}$, Desti Ranihusna ${ }^{2}$, Rini Widyastuti ${ }^{3}$ \\ ${ }^{1}$ Fakultas Ekonomi, Universitas Negeri Semarang, Indonesia \\ ${ }^{2}$ Fakultas Ekonomi, Universitas Negeri Semarang, Indonesia \\ ${ }^{3}$ Fakultas Ekonomi, Universitas Negeri Semarang, Indonesia
}

\begin{tabular}{l}
\hline ARTICLE INFORMATION \\
\hline ISSN: 2579-7204 (Online) \\
ISSN: 0216-4132 (Print) \\
DOI: $10.26487 /$ jbmi.v18i3.18492 \\
\hline SUBMISSION TRACK \\
\hline Received: 27 October 2021 \\
Final Revision: 20 January 2022 \\
Available Online: 24 February, 2022 \\
\hline KATA KUNCI \\
Praktik Manajemen Perubahan yang \\
Efektik; Kinerja; $\quad$ Kesejahteraan; \\
Pegawai Eselon III dan IV; Universitas \\
Negeri Semarang
\end{tabular}

\begin{abstract}
ABSTRAK
Penghapusan jabatan eselon III dan IV telah diserukan Kementerian Pendayagunaan Aparatur Negara dan Reformasi Birokrasi (Kemen PAN-RB) yang telah dijalankan sejak tahun 2012 memungkinkan menimbulkan banyak dampak. Universitas Negeri Semarang, sebagai institusi Pendidikan tinggi berusaha untuk beradaptasi atas perubahan tersebut melalui praktik manajemen perubahan sejak diberlakukan Surat Keputusan Fungsional pada 29 Desember tahun 2020. Upaya adaptasi melalui praktik manajemen perubahan perlu diperiksa lebih lanjut apakah berdampak pada tingkat kinerja dan kesejahteraan pegawai eselon III dan IV Universitas Negeri Semarang. Tujuan dari penelitian ini untuk mengetahui pengaruh praktik manajemen perubahan pada kinerja dan kesejahteraan. Metode penelitian yang digunakan adalah penelitian kuantitatif dengan menggunakan kuesioner sebagai instrument penelitian dan disebarkan kepada 81 pegawai eselon III dan IV, tingkat pengembalian kuesioner 96\% (78 responden). Analisis data pada penelitian ini menggunakan metode SEM-PLS dengan alat analisis SmartPLS 3.0. Hasil penelitian menyatakan bahwa Universitas Negeri Semarang telah berhasil menerapkan praktik manajemen perubahan, sehingga ditemukan pengaruh positif dan signifikan pada tingkat kinerja dan kesejahteraan pegawai eselon III dan IV, dan seluruh hipotesis yang diajukan dalam penelitian ini dapat diterima.
\end{abstract}

\begin{tabular}{l} 
KEYWORD \\
\hline Effective Change Management; \\
Performance; Well-Being; Eselon III \\
and IV Employee; Universitas Negeri \\
Semarang
\end{tabular}

\section{CORRESPONDENCE}

Phone: +6285865664 756

E-mail: kamtono@mail.unnes.ac.id

\begin{abstract}
The abolition of echelon III and IV positions has been called for by Kementerian Pendayagunaan Aparatur Negara dan Reformasi Birokrasi (Kemen PAN-RB), has been implemented since 2012 allowing many impacts. Universitas Negeri Semarang as a higher education institution has tried to adapt to these changes through change management practices since the Functional Decree was enacted on 29 December 2020. The effort to adapt through change management practices needs to be further examined whether it has an impact on the level of performance
\end{abstract}


and well-being of echelon III and III employees of Universitas Negeri Semarang. The purpose of this research is to determine the effect of change management practices on performance and welfare. The research methods is quantitative research used a questionnaire as an instrument and distributed to 81 echelons III and IV employees, the return rate of the questionnaire is $96 \%$ (78 respondents). Data analysis in this study used the SEM-PLS method with the SmartPLS 3.0 analysis tool. Results showed that Universitas Negeri Semarang has succeeded in implementing change management practices so that a positive and significant effect was found on the level of performance and well-being of echelon III and IV employees, and all hypotheses proposed in this study were accepted.

\section{PENDAHULUAN}

Penghapusan jabatan eselon III dan IV telah diserukan Kementerian Pendayagunaan Aparatur Negara dan Reformasi Birokrasi (Kemen PAN-RB) dan mulai dijalankan pada tahun 2012, penghapusan ini bertujuan untuk memindahkan orientasi pegawai dari jabatan struktural ke jabatan fungsional, sehingga dapat mengurangi biaya yang tidak diperlukan seperti fasilitas dinas dan jabatan pegawai eselon III dan IV. Selain itu, alasan penghapusan ini juga dikarenakan banyak tugas dilingkungan kementerian, lembaga, dan pemerintah daerah yang seharusnya dikerjakan 1 (satu) orang tetapi justru dikerjakan 10 orang, dan hal ini tentu menimbulkan pemborosan biaya dan kinerja pegawai tidak efektif.

Kelembagaan Kemen PAN-RB, Ismadi Ananda, menjelaskan pemerintah tidak hanya menjalankan program penghapusan ini begitu saja. Akan tetapi, sejak awal sudah menyiapkan upaya untuk memberikan kompensasi bagi pegawai yang menduduki jabatan-jabatan tersebut. Kompensasi yang paling utama adalah pemerintah menambah pos jabatan fungsional di antaranya menambah 200 unit pos jabatan termasuk di dalamnya adalah analis-analisis (jabatan, pegawai, keuangan, dan auditor) (Antara, 2013). 
Adanya analis-analis ini diharapkan dapat mempermudah penataan kelembagaan, namun di sisi lain akan menimbulkan dampak penyetaraan pejabat administrasi. Untuk itu, diterbitkan Peraturan MenPAN-RB Nomor 28/2019 tentang penyetaraan jabatan administrasi ke dalam jabatan fungsional untuk menjamin kepastian dan pengembangan karier pejabat administrasi yang terdampak penyederhanaan birokrasi. Regulasi baru ini sebagai instrumen untuk memberikan peluang pengembangan karier agar organisasi tetap dapat berjalan dengan sistem karier berbasis fungsional.

Berdasarkan kebijakan yang ada dari pemerintah pusat, maka Universitas Negeri Semarang turut mengapresiasi dengan memberlakukan perubahan jabatan struktural menjadi fungsional bagi Kepala Bagian dan Kepala Sub-bagian sejak diberlakukan Surat Keputusan Fungsional pada 29 Desember tahun 2020. Perubahan jabatan struktural menjadi fungsional tersebut merupakan salah satu bentuk dari praktik manajemen perubahan, karena Universitas Negeri Semarang semakin menyadari dan menghargai pentingnya praktik manajemen perubahan, selain sebagai bentuk dukungan dan kepatuhan terhadap peraturan yang telah diterbitkan.

Adaptasi institusi pendidikan tinggi yang tepat waktu dan berkelanjutan terhadap perubahan yang terjadi di lingkungan eksternal membutuhkan pertimbangan yang sangat matang, dengan demikian perubahan menjadi prasyarat utama untuk kelangsungan hidup dan pertumbuhan institusi, dan hal ini penting bagi manajemen Universitas untuk memastikan perumusan dan implementasi rencana perubahan secara efektif untuk tetap mempertahankan dan mencapai tingkat kinerja yang tinggi, dan memastikan bahwa perubahan tersebut tidak menyebabkan dampak terhadap rendahnya kesehaan dan kesejahteraan pegawai (Chepkurgat et al., 2019); (Zehra \& Siddiqui, 2019).

Penelitian sebelumnya yang dilakukan oleh (Thomas, 2014; Wanza \& Nkuraru, 2016; Menda et al., 2018; Kahoro \& Rugami, 2018; Kojo et al., 2019; Kimhi et al., 2019; Ratnasari et al., 2020; Harahap, 2020) menemukan bahwa implementasi manajemen perubahan yang efektif dalam seluruh sektor memberikan dampak positif yang signifikan bagi kinerja pegawai. Berbeda dengan penelitian yang dilakukan Mudeng et al., (2017) yang menemukan bahwa perubahaan organisasi tidak berpengaruh signifikan pada kinerja karyawan. Perubahan seperti restrukturisasi, perampingan, atau penggabungan yang sedang berlangsung memungkinkan membawa 
dampak kurang percaya diri, stres, bahkan burnout pada karyawan, sehingga membuat karyawan enggan menerimanya secara sukarela (Khosa et al., 2015).

Beberapa kasus mengungkapkan dampak restrukturisasi yang berkepanjangan akan berpengaruh negatif pada kesejahteraan seperti persepsi kekhawatiran secara psikologis (psychological well-being) (Bamberger et al., 2012), dan bagaimana perubahan tersebut akan memengaruhi tugas dan pekerjaan mereka dalam organisasi (workplace well-being), serta kesejahteraan kehidupan (life well-being) (Smollan, 2015). Tetapi tidak semua, restrukturisasi dapat mengarah pada peningkatan kesejahteraan yang lebih baik jika direncanakan, diorganisasikan dan dikelola secara efektif (Wiezer et al., 2011).

Berdasarkan latar belakang tersebut, peneliti tertarik untuk mengkonseptualisasikan dan berkontribusi untuk memberikan gambaran terkait dampak perubahan atau restrukturasi yang dilakukan akan memengaruhi kinerja dan kesejahteraan pegawai Eselon III dan IV di lingkungan Universitas Negeri Semarang.

\section{TINJAUAN PUSTAKA}

Manajemen perubahan merupakan sebuah proses sistematis atau pendekatan yang terstruktur dan melalui proses perencanaan, pengorganisasian, implementasi dan pengelolaan/pengendalian atas aktivitas atau program perubahan yang akan dilakukan oleh organisasi (Wibowo, 2016). Pada praktik manajemen perubahan, dibutuhkan keterampilan dan strategi manajerial yang tepat, sehingga organisasi atau perusahaan dapat bertahan, berhasil dan tetap kompetitif dalam lingkungan bisnis yang sangat dinamis dan fluktuatif,

Menurut Kamus Besar Bahasa Indonesia (KBBI), arti jabatan struktural adalah jabatan yang terdapat dalam struktur organisasi (komunitas) secara formal sehingga tugas, tanggung jawab, wewenang dan hak pejabat atau pegawai bersangkutan sudah diatur. Jabatan struktural sesuai dengan namanya, pemilik jabatan ini berkedudukan dalam struktur organisasi, sedangkan Jabatan fungsional yaitu jabatan teknis yang tidak tercantum dalam struktur organisasi, tetapi dari sudut pandang fungsinya sangat diperlukan dalam pelaksansaan tugas-tugas pokok organisasi.

Bin Shmailan (2016) menyatakan bahwa kinerja pada dasarnya adalah apa yang dilakukan dan tidak dilakukan oleh pegawai atau karyawan. Kinerja juga dianggap 
sebagai proses sejauh mana seseorang pegawai atau karyawan dapat melaksanakan strategi perusahaan baik dalam pencapaian tujuan dan atau peran individu untuk menunjukkan kompetensinya yang relevan (Harwiki, 2016).

Konsep kesejahteraan (well-being) karyawan ditempat kerja merupakan konsep yang cukup luas dengan berbagai pandangan. Menurut Undang-Undang No. 13 Tahun 2003 tentang Ketenagakerjaan, kesejahteraan merupakan suatu pemenuhan dan atau keperluan yang bersifat jasmaniah dan rohaniah, yang secara langsung atau tidak langsung berkaitan dengan produktivitas kerja.

Organisasi atau perusahaan harus mampu mengelola perubahan agar tidak berdampak negatif pada organisasi dan orang-orang yang terlibat dalam perubahan tersebut, termasuk karyawan. Wiezer et al., (2011) mengungkapkan bahwa dari semua analisis, menunjukkan bahwa restrukturisasi akan berdampak pada kesejahteraan karyawan di organisasi sebelum, selama, dan setelah restrukturisasi. Perubahan akan berdampak pada aspek pekerjaan: kinerja, kepuasaan, dedikasi, kesejahteraan, sinisme, kelelahan emosional, stres, dan job insecurity.

Kitur (2015) berpendapat bahwa bentuk dari perubahaan organisasi dapat berupa: merger, joint venture, kepemimpinan baru, implementasi teknologi baru, restrukturisasi, perubahaan produk, atau kepatuhan terhadap peraturan yang baru ditetapkan. Perubahan mungkin dapat direncanakan bertahun-tahun, tetapi perubahan juga dapat berupa paksaan karena adanya pergeseran dalam lingkungan bisnis secara cepat dan signifikan.

Perubahaan merupakan hal yang tidak dapat dihindari, untuk itu penting mempelajari bagaimana faktor perubahaan dapat memengaruhi kinerja karyawan dan juga kesejahteraan mereka ditempat kerja. Berdasarkan penjelasan tersebut, maka hipotesis yang dapat dirumuskan adalah sebagai berikut:

H.1 Praktik manajemen perubahan berpengaruh signifikan pada kinerja pegawai

H.2 Praktik manajemen perubahan berpengaruh signifikan pada kesejahteraan pegawai.

H.3 Kesejahteraan pegawai berpengaruh signifikan pada kinerja pegawai.

H.4 Kesejahteraan pegawai memediasi pengaruh praktik manajemen perubahan pada kinerja pegawai. 


\section{METODE PENELITIAN}

Objek penelitian ini adalah Universitas Negeri Semarang dengan melibatkan pegawai eselon III dan IV. Jenis penelitian yang dibangun adalah penelitian kuantitatif. Teknik pengambilan sampel pada penelitian ini adalah sampel jenuh, yaitu teknik pengambilan sampel dengan melibatkan seluruh anggota populasi sejumlah 81 pegawai, dan diperoleh 78 pegawai sebagai sampel. Metode pengambilan data menggunakan data primer dengan metode kuesioner (angket) dengan pengukurannya menggunakan skala Likert 1-5.

Item pernyataan keseluruhan berjumlah 19 item. Variabel kesejahteraan pegawai (change in management) terdapat 10 item pernyataan yang diadopsi dari Hayes dan Hyde (2016) dengan contoh item pernyataan "Universitas memberikan penjelasan yang jelas kepada saya tentang mengapa ingin melakukan perubahan”. Variabel kinerja karyawan (employee performance) terdapat 6 item yang diadopsi dari Pradhan dan Jena (2017), dengan contoh item pernyataan "saya dapat mengelola perubahan dalam pekerjaan saya dengan baik bagaimanapun situasinya".

Variabel kesejahteraan pegawai (employee well-being) terdapat 3 item pernyataan yang di adopsi dari Zheng et al. (2015), dengan contoh item pernyataan "Meskipun organisasi tempat saya bekerja (Unnes) melakukan perubahan, saya tetap dapat menemukan cara untuk meningkatkan kualitas pekerjaan saya”. Metode analisis data pada penelitian ini menggunakan structural equation model-partial least square dengan bantuan alat analisis program SmartPLS 3.0.

\section{HASIL DAN DISKUSI}

\section{A. Karakteristik Responden}

Karakteristik responden pada penelitian ini akan dijelaskan ke dalam beberapa jenis karakteristik antara lain berdasarkan jenis kelamin, usia, dan masa kerja. Total responden pada penelitian ini adalah sebanyak 78 responden/pegawai eselon III dan IV Universitas Negeri Semarang. Berikut hasil analisisnya: 
JURNAL BISNIS, MANAJEMEN, DAN INFORMATIKA (JBMI) - VOL 18 NO. III (2022)

Tabel 1. Karakteristik Responden Berdasarkan Jenis Kelamin

\begin{tabular}{lcc}
\hline \multicolumn{1}{c}{ Jenis Kelamin } & Frekuensi & Persentase \\
\hline Laki-Laki & 38 & $48,7 \%$ \\
Perempuan & 40 & $51,3 \%$ \\
\hline
\end{tabular}

Sumber: Data Primer, 2021 (diolah)

Berdasarkan tabel 1 dapat diketahui bahwa jumlah pegawai yang berjenis kelamin perempuan dan laki-laki tidak memiliki perbedaan yang signifikan, masing-masing adalah $51,3 \%$ dan $48,7 \%$

Tabel 2. Karakteristik Responden Berdasarkan Usia

\begin{tabular}{ccc}
\hline $\begin{array}{c}\text { Interval Umur } \\
\text { (Tahun) }\end{array}$ & Frekuensi & Persentase \\
\hline $27-30$ & 3 & $3,85 \%$ \\
$31-35$ & 2 & $2,56 \%$ \\
$36-39$ & 7 & $8,97 \%$ \\
$40-43$ & 19 & $24,36 \%$ \\
$44-47$ & 12 & $15,38 \%$ \\
$48-51$ & 9 & $11,54 \%$ \\
$52-58$ & 26 & $33,33 \%$ \\
\hline
\end{tabular}

Sumber: Data Primer, 2021 (diolah)

Berdasarkan tabel 2 dapat diketahui bahwa karakteristik responden berdasarkan usia yang memiliki frekuensi tertinggi yaitu responden dengan rentang usia 52-58 sebanyak 26 orang $(33,33 \%)$.

Tabel 3. Karakteristik Responden Berdasarkan Masa Kerja

\begin{tabular}{ccc}
\hline $\begin{array}{c}\text { Interval Masa Kerja } \\
\text { (Tahun) }\end{array}$ & Frekuensi & Persentase \\
\hline $5-8$ & 3 & $3,85 \%$ \\
$9-12$ & 7 & $8,97 \%$ \\
$13-16$ & 23 & $29,49 \%$ \\
$17-20$ & 13 & $16,67 \%$ \\
$21-24$ & 6 & $76,9 \%$ \\
$25-28$ & 8 & $10,26 \%$ \\
$29-36$ & 18 & $23,08 \%$ \\
\hline
\end{tabular}

Sumber: Data Primer, 2021 (diolah) 
Berdasarkan tabel 3 dapat diketahui bahwa karakteristik responden berdasarkan masa kerja yang memiliki frekuensi tertinggi yaitu responden dengan rentang masa kerja 13-16 sebanyak 23 orang $(29,49 \%)$.

\section{B. Analisis Deskripstif}

Analisis deskriptif berfungsi untuk menjabarkan dan memberikan gambaran terhadap jawaban responden atas pernyataan kuesioner yang diajukan (Ferdinand, 2014). Analisis deskriptif diuji menggunakan bantuan alat analisis berupa IBM SPSS Versi. 23.

Pada penelitian ini, analisis deskriptif digunakan untuk menganalisis atau menggambarkan karakteristik demografi dan variabel penelitian. Analisis deskriptif karakteristik demografi responden yang akan dideskripsikan dalam penelitian ini adalah jenis kelamin, usia, jenjang pendidikan, masa kerja, dan status kepegawaian.

Analisis deskriptif variabel penelitian yang akan dideskripsikan dalam penelitian ini menggunakan nilai kriteria interval (theree-box method) yang dihitung terlebih dahulu nilai indeksnya. Berdasarkan perhitungan nilai indeks untuk kriteria nilai interval maka dihasilkan nilai indeks yang dimulai dengan angka 22,4 - 52,26 (rendah), 52,27 - 82,13 (sedang), dan 82,14 - 112 (tinggi) (Ferdinand, 2014).

Secara deskriptif, rata-rata nilai indeks yang diperoleh untuk praktik manajemen perubahan (change in management) adalah sebesar 72,82 yang termasuk dalam kategori sedang, variabel kinerja pegawai (employee performance) sebesar 79,10 yang termasuk dalam kategori tinggi, dan variabel kesejahteraan pegawai (employee well-being) sebesar 82,90 yang termasuk dalam kategori tinggi.

\section{Uji Outer Model}

\section{Uji Validitas Konvergen}

Dasar pengambilan keputusan untuk uji validitas konvergen adalah dengan melihat nilai outer loading dan nilai average variance extracted (AVE). Sebuah item pernyataan dapat dikatakan valid konvergen apabila nilai outer loading memiliki konsitensi internal 0.6-0.7 dan atau nilai average variance extracted (AVE) > 0.5 (Hair et al., 2017); (Ghozali \& Latan, 2015); (Santosa, 2018). Hasil pengolahan data untuk validitas konvergen menunjukkan bahwa item pernyataan CIM 1 (variabel change in management) harus dihapus dari model penelitian karena memiliki nilai outer loading < 
0.6, dan item pernyataan EP 5 (variabel employee performance), dihapus dari model penelitian karena memiliki nilai Average variance extracted $(\mathrm{AVE})<0.5$. Berikut hasil pengolahan data untuk validitas konvergen.

Tabel 4. Hasil Uji Validitas Konvergen

\begin{tabular}{|c|c|c|c|c|}
\hline Variabel & $\begin{array}{c}\text { Item } \\
\text { Pernyataan }\end{array}$ & $\begin{array}{l}\text { Nilai Outer } \\
\quad \text { loading }\end{array}$ & Keterangan & $\begin{array}{c}\text { Average } \\
\text { Variance } \\
\text { Extracted } \\
\text { (AVE) }\end{array}$ \\
\hline \multirow{9}{*}{$\begin{array}{l}\text { Change In } \\
\text { Management }\end{array}$} & CIM.2 & 0.670 & Valid & \multirow{9}{*}{0.570} \\
\hline & CIM.3 & 0.745 & Valid & \\
\hline & CIM.4 & 0.775 & Valid & \\
\hline & CIM.5 & 0.849 & Valid & \\
\hline & CIM.6 & 0.821 & Valid & \\
\hline & CIM.7 & 0.679 & Valid & \\
\hline & CIM.8 & 0.800 & Valid & \\
\hline & CIM.9 & 0.764 & Valid & \\
\hline & CIM.10 & 0.667 & Valid & \\
\hline \multirow{3}{*}{$\begin{array}{l}\text { Employee } \\
\text { Well-Being }\end{array}$} & EWB1 & 0.766 & Valid & \multirow{3}{*}{0.692} \\
\hline & EWB2 & 0.858 & Valid & \\
\hline & EWB3 & 0.867 & Valid & \\
\hline \multirow{5}{*}{$\begin{array}{l}\text { Employee } \\
\text { Performance }\end{array}$} & EP1 & 0.718 & Valid & \multirow{5}{*}{0.502} \\
\hline & EP2 & 0.690 & Valid & \\
\hline & EP3 & 0.798 & Valid & \\
\hline & EP4 & 0.683 & Valid & \\
\hline & EP6 & 0.644 & Valid & \\
\hline
\end{tabular}

Sumber : Data Primer, 2021 (diolah)

\section{Uji Validitas Diskriminan}

Untuk melihat apakah indikator reflektif memiliki validitas diskriminan adalah dengan melihat nilai perbandingan antara outer loading dan cross loading, apabila nilai outer loading lebih besar daripada nilai crossloading maka indikator reflektif memenuhi asumsi validitas diskriminan (Solimun et al., 2017). Tabel 5 merupakan hasil uji validitas diskriminan untuk penelitian ini. 
Tabel 5. Hasil Uji Validitas Diskriminan

\begin{tabular}{ccccc}
\hline & $\begin{array}{c}\text { Change } \\
\text { Management }\end{array}$ & $\begin{array}{c}\text { Employee } \\
\text { Well-Being }\end{array}$ & $\begin{array}{c}\text { Employee } \\
\text { Performance }\end{array}$ & Keterangan \\
\hline CIM.2 & $\mathbf{0 . 6 7 0}$ & 0,255 & 0,423 & Valid \\
\hline CIM.3 & $\mathbf{0 . 7 4 5}$ & 0,320 & 0,337 & Valid \\
CIM.4 & $\mathbf{0 . 7 7 5}$ & 0,336 & 0,210 & Valid \\
CIM.5 & $\mathbf{0 . 8 4 9}$ & 0,315 & 0,433 & Valid \\
CIM.6 & $\mathbf{0 . 8 2 1}$ & 0,348 & 0,399 & Valid \\
CIM.7 & $\mathbf{0 . 6 7 9}$ & 0,161 & 0,357 & Valid \\
CIM.8 & $\mathbf{0 . 8 0 0}$ & 0,330 & 0,280 & Valid \\
CIM.9 & $\mathbf{0 . 7 6 4}$ & 0,210 & 0,331 & Valid \\
CIM.10 & $\mathbf{0 . 6 6 7}$ & 0.199 & 0,108 & Valid \\
EWB1 & 0,286 & $\mathbf{0 . 7 6 6}$ & 0,387 & Valid \\
EWB2 & 0,272 & $\mathbf{0 . 8 5 8}$ & 0,384 & Valid \\
EWB3 & 0,357 & $\mathbf{0 . 8 6 7}$ & 0,569 & Valid \\
EP1 & 0,280 & 0,404 & $\mathbf{0 . 7 1 8}$ & Valid \\
EP2 & 0,410 & 0,395 & $\mathbf{0 . 6 9 0}$ & Valid \\
EP3 & 0,244 & 0,488 & $\mathbf{0 . 7 9 8}$ & Valid \\
EP4 & 0,263 & 0,218 & $\mathbf{0 . 6 8 3}$ & Valid \\
EP6 & 0,362 & 0,385 & $\mathbf{0 . 6 4 4}$ & Valid \\
\hline
\end{tabular}

Sumber : Data Primer, 2021 (diolah)

Berdasarkan tabel 5 dapat diketahui bahwa semua item pernyataan dari masingmasing konstruk memiliki nilai outer loading yang lebih besar daripada nilai cross loading, sehingga dapat disimpulkan bahwa semua indikator/item penyataan dalam penelitian ini adalah valid secara diskriminan dan memiliki nilai diskriminan yang baik.

\section{Uji Reliabilitas}

Dasar pengambilan keputusan untuk menilai apakah instrumen reliabel apabila nilai konsistensi internalnya antara $0,6-0,7$ dan nilai antara $0,7-0,9$ adalah memuaskan. Nilai konsistensi internal yang lebih besar dari 0,95 justru tidak di inginkan karena hal ini menunjukkan bahwa indikator mengukur fenomena yang sama sehingga indikatorindikator tersebut tidak valid secara diskriminan untuk mengukur konstruknya (Santosa, 2018); (Hair et al., 2017). Tabel 6 merupakan hasil uji reliabilitas untuk penelitian ini.

Tabel 6. Hasil Uji Reliabilitas 


\begin{tabular}{lccc}
\hline \multicolumn{1}{c}{ Variabel } & $\begin{array}{c}\text { Composite } \\
\text { Reliability }\end{array}$ & $\begin{array}{c}\text { Cronbanch } \\
\text { Alpha's }\end{array}$ & Keterangan \\
\hline Change In Management & 0.922 & 0.905 & Reliabel \\
Employee Well-Being & 0.870 & 0.780 & Reliabel \\
Employee Performance & 0.833 & 0.752 & Reliabel \\
\hline
\end{tabular}

Sumber: Data Primer, 2021 (diolah)

Berdasarkan tabel 6 dapat dilihat bahwa seluruh konstruk pada penelitian ini memiliki nilai composite reliability dan nilai cronbach alpha $>0.7$ dan tidak melebihi batas maksimal 0.95, sehingga dapat disimpulkan bahwa semua konstruk pada penelitian ini adalah reliabel.

\section{Uji Inner Model}

Gambar 1. Hasil Uji Inner Model (Boostrapping)

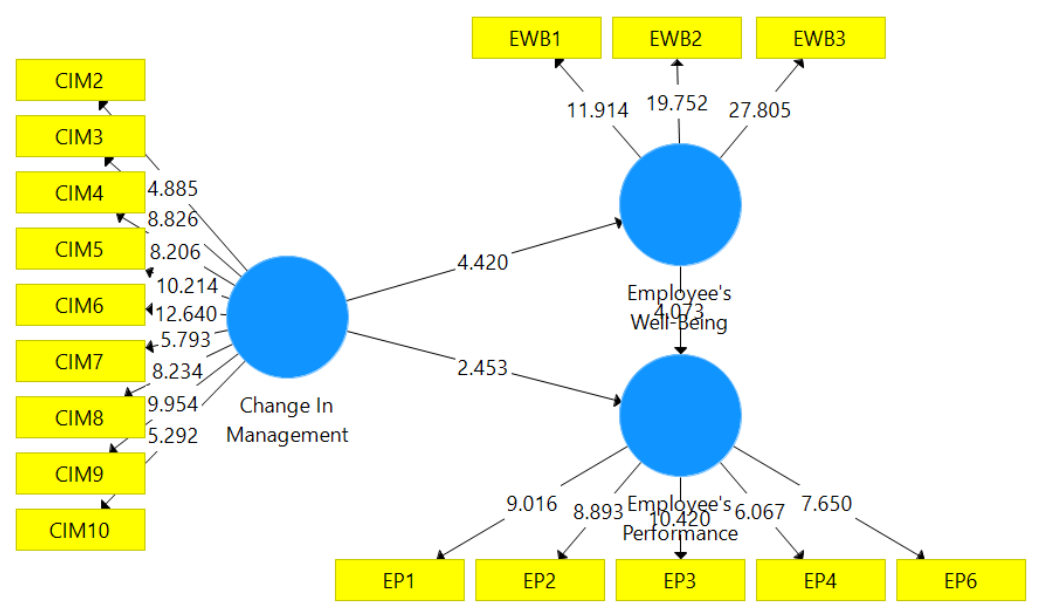

Sumber: Data Primer, 2021 (diolah)

\section{Asesmen Kolinearitas}

Untuk menilai apakah konstruk-konstruk pada penelitian ini terdapat persoalan kolinearitas adalah menggunakan nilai VIF $<5$ dan atau toleransi $>0.2$ (Santosa, 2018) Tabel 7 merupakan hasil uji kolinearitas pada penelitian ini. 
Tabel 7. Hasil Uji Kolinearitas

\begin{tabular}{|c|c|c|c|}
\hline & $\begin{array}{c}\text { Change In } \\
\text { Management }\end{array}$ & $\begin{array}{c}\text { Employee Well- } \\
\text { Being }\end{array}$ & $\begin{array}{c}\text { Employee } \\
\text { Performance }\end{array}$ \\
\hline Change In Management & & 1.000 & 1.162 \\
\hline Employee Well-Being & & & 1.162 \\
\hline Employee Performance & & & \\
\hline
\end{tabular}

Sumber : Data Primer, 2021 (diolah)

Berdasarkan tabel 4.7 diatas dapat dilihat bahwa nilai VIF inner model untuk masing-masing konstruk pada penelitian ini memiliki nilai $\mathrm{VIF}<5$, sehingga dapat disimpulkan bahwa 2 konstruk yang saling berkaitan tidak memiliki persoalan kolinearitas.

\section{Effect Size}

Sebuah konstruk dikatakan memiliki nilai effect size yang cukup apabila nilai f2 diperoleh lebih dari 0 , apabila nilai f2 memiliki nilai dibawah 0 maka terbukti bahwa konstruk tersebut tidak memiliki effect size yang cukup. Kategori untuk nilai f2 yaitu 0.02, 0.15, 0.35 menunjukkan pengaruh kecil, sedang, besar (Santosa, 2018). Tabel 8 merupakan hasil uji effect size untuk penelitian ini.

Tabel 8. Hasil Uji Effect Size

\begin{tabular}{ccc}
\hline Variabel & Effect Size & Kategori \\
\hline Change in Management - Employee Well-Being & 0,162 & Sedang \\
Change in Management - Employee Performance & 0.107 & Sedang \\
Employee Well-Being - Employee Performance & 0.277 & Besar \\
\hline
\end{tabular}

Sumber : Data Primer, 2021 (diolah)

\section{Relevansi Prediktif}

Untuk menilai relevansi prediktif (Q2) adalah jika nilai Q2 lebih besar dari nol maka kontruk endogen tertentu mempunyai relevansi prediktif. Jika nilai Q2 sama dengan atau lebih kecil dari 0 menunjukkan tidak adanya relevansi prediktif (Santosa, 2018). Tabel 9 merupakan hasil uji relevansi prediktif untuk penelitian ini.

Tabel 9. Hasil Uji Relevansi Prediktif $\left(Q^{2}\right)$

\begin{tabular}{|c|c|c|c|}
\hline Variabel & SSE & SSO & $\mathbf{Q}^{2}=1-(\mathrm{SSE} / \mathrm{SSO})$ \\
\hline Employee Well-Being & 330.181 & 390.000 & 0.153 \\
\hline Employee Performance & 213.530 & 234.000 & 0.087 \\
\hline
\end{tabular}


Sumber : Data Primer, 2021 (diolah)

Berdasarkan tabel 9 dapat dilihat bahwa nilai Q2 untuk konstruk endogen kesejahteraan pegawai (employee well-beingI) adalah sebesar 0.153 dan kinerja pegawai (employee performance) sebesar 0.087, sehingga dapat dikatakan bahwa konstruk endogen dalam penelitian ini memiliki relevansi prediktif $(>0)$, sehingga dapat diinterpretasikan bahwa model penelitian secara akurat dapat memprediksi data yang tidak digunakan untuk mengevaluasi model tersebut.

\section{Koefisien Determinasi}

Untuk dapat menilai koefisien determinasi adalah dengan melihat nilai R2 dan mengkalikannya dengan 100\%. Tabel 10 merupakan hasil perhitungan nilai koefisien determinasi untuk penelitian ini.

Tabel 10. Hasil Uji Koefisien Determinasi

\begin{tabular}{lcc}
\hline \multicolumn{1}{c}{ Variabel } & Nilai $\mathbf{R}^{\mathbf{2}}$ & Koefisien Determinasi \\
\hline Employee Well-Being & 0.373 & $37,3 \%$ \\
\hline Employee Performance & 0.139 & $13,9 \%$ \\
\hline
\end{tabular}

Sumber : Data Primer, 2021 (diolah)

Berdasarkan tabel 10 dapat dilihat bahwa nilai koefisien determinasi yang diperoleh adalah sebesar 37,3\% untuk variabel kesejahteraan pegawai (employee well-being) dan 13,9\% untuk variabel kinerja pegawai (employee performance).

Hal ini dapat diinterpretasikan bahwa variasi nilai variabel kesejahteraan pegawai (employee well-being) dapat dijelaskan variabel praktik manajemen perubahan (change in management) sebesar 37,3\% dan sisanya $62,7 \%$ dijelaskan oleh variabel lain di luar dari model yang diteliti. Selain itu, variasi nilai variabel kinerja pegawai (employee performance) dapat dijelaskan variabel praktik manajemen perubahan (change in management) sebesar $13,9 \%$ dan sisanya $86,1 \%$ dijelaskan oleh variabel lain di luar model yang diteliti.

\section{Uji Hipotesis}

Pengujian hipotesis dilihat berdasarkan nilai original sampel, t-statistic dan p-value menggunakan prosedur bootstraping. Hipotesis dapat diterima apabila nilai t-statistic lebih besar daripada 1.991 (two tailed) dengan p-value $>0.05$, nilai original sample menunjukkan arah hubungan dari hipotesis yang diuji. Tabel 11 merupakan hasil uji hipotesis pada penelitian ini. 
Tabel 11. Hasil Uji Hipotesis

\begin{tabular}{lcccc}
\hline & $\begin{array}{c}\text { Original } \\
\text { Sample }\end{array}$ & T-Statistic & P-Value & Keterangan \\
\hline & Direct Effect & & \\
\hline $\begin{array}{l}\text { Change In Management -Employee } \\
\text { Performance }\end{array}$ & 0.279 & 2.453 & 0.015 & HI Diterima \\
\hline $\begin{array}{l}\text { Change In Management-Employee } \\
\text { Well-Being }\end{array}$ & 0.373 & 4.420 & 0.000 & H2 Diterima \\
\hline $\begin{array}{l}\text { Employee Well-Being-Employee } \\
\text { Performance }\end{array}$ & 0.449 & 4.073 & 0.000 & H3 Diterima \\
\hline $\begin{array}{l}\text { Indirect Effect } \\
\text { Change In Management - Employee } \\
\text { Well-Being - Employee Performance }\end{array}$ & 0.167 & 3.173 & 0.002 & H4 Diterima \\
\hline
\end{tabular}

Sumber : Data Primer, 2021 (diolah)

Berdasarkan tabel 11 dapat diinterpretasikan hasil uji hipotesis (pengaruh langsung dan tidak langsung) sebagai berikut:

1. Praktik manajemen perubahan (change in management) berpengaruh positif pada kinerja pegawai (employee performance) dengan nilai original sample sebesar 0.279 dan $t$-statistic $2.453>1.991$ dan $p$-value $0.015<0.050$.

2. Praktik manajemen perubahan (change in management) berpengaruh positif pada kesejahteraan pegawai (employee well-being) dengan nilai original sample sebesar 0.373 dan $t$-statistic $4.420>1.991$ dan $p$-value $0.000<0.050$.

3. Kesejahteraan pegawai (employee well-being) berpengaruh positif pada kinerja pegawai (employee performance) dengan nilai original sample sebesar 0.449 dan $t$-statistic $4.073>1.991$ dan $p$-value $0.000<0.050$.

4. Praktik manajemen perubahan (change in management) berpengaruh positif pada kinerja pegawai (employee performance) melalui kesejahteraan pegawai (employee well-being) dengan nilai original sample sebesar 0.167 dan $t$ statistic $3.173>1.991$ dan $p$-value $0.002<0.050$.

\section{Pembahasan}

Perubahan merupakan hal yang tidak dapat dihindari, setiap instansi/organisasi/perusahaan akan selalu berubah mengikuti apa yang terjadi di lingkungannya. Perubahan akan membawa dampak baik apabila direncanakan, dikelola, dan dilaksanakan dengan efektif. Perubahan yang baik adalah perubahan yang dirancang secara sistematis atau terstruktur, sehingga tujuan dari perubahan dapat 
didefinisikan dengan jelas. Praktik manajemen perubahan membantu para stakeholder untuk dapat mengelola perubahan dengan baik, sehingga persepsi atas perubahaan yang dirasakan karyawan /pegawai dapat dikendalikan agar tidak membawa dampak buruk terhadap organisasi, pekerjaan, atau bahkan kehidupan mereka.

Sebagai bentuk dukungan dan kepatuhan terhadap peraturan yang telah ditetapkan yaitu Peraturan MenPAN-RB Nomor 28/2019 tentang penyetaraan jabatan administrasi ke dalam jabatan fungsional untuk menjamin kepastian dan pengembangan karier pejabat administrasi yang terdampak penyederhanaan birokrasi, Universitas Negeri Semarang sebagai institusi pendidikan tinggi, turut ikut serta untuk memberlakukan perubahan jabatan struktural menjadi fungsional bagi Kepala Bagian dan Kepala Subbagian (pegawai eselon III dan IV) di lingkungan Universitas Negeri Semarang. Perubahan ini merupakan bentuk adaptasi institusi pendidikan tinggi atas apa yang telah ditetapkan, dengan begitu Universitas Negeri Semarang berusaha untuk menerapkan perubahan tersebut melalui praktik manajemen perubahan.

Praktik manajemen perubahan merupakan proses yang sistematis dan terstruktur untuk menerapkan perubahan melalui perencanaan, pengorganisasian, implementasi dan pengelolaan/pengendalian atas aktivitas atau program perubahan yang akan dilakukan sehingga diharapkan perubahan tidak berdampak negatif pada organisasi dan pegawai/karyawan termasuk rendahnya tingkat kinerja dan kesejahteraan pegawai. Hal ini sesuai dengan penelitian yang dilakukan oleh Sinaga et al. (2018) yang mengungkapkan bahwa manajemen perubahan akan memengaruhi beberapa hal yang secara spesifik tertuju pada pegawai atau karyawan salah satunya adalah kinerja dan kesejahteraan.

Berdasarkan hasil uji hipotesis yang ditampilkan pada tabel 11 mengungkapkan bahwa praktik manajemen perubahan (change in management) atau dalam hal ini proses perencanaan, pengorganisasian, dan pengelolaan atas perubahan jabatan struktural ke dalam jabatan fungsional pada pegawai eselon III dan IV di lingkungan Universitas Negeri Semarang dapat dikatakan efektif sesuai dengan hasil penelitian yang menunjukkan bahwa praktik manajemen perubahan (change in management) berpengaruh signifikan pada kinerja dan kesejahteraan baik pengaruh langsung dan tidak langsung, arah hubungan di antara variabel tersebut adalah positif, sehingga semakin baik praktik manajemen perubahan yang dilakukan maka semakin meningkat 
kinerja dan kesejahteraan pegawai eselon III dan IV di lingkungan Universitas Negeri Semarang.

Hasil penelitian, sesuai dengan penelitian yang dilakukan oleh (Thomas, 2014; Wanza \& Nkuraru, 2016; Menda et al., 2018; Kahoro \& Rugami, 2018; Kojo et al., 2019; Kimhi et al., 2019;Ratnasari et al., 2020; Harahap, 2020) yang menemukan bahwa praktik manajemen perubahan yang dilakukan secara efektif akan memberikan dampak positif pada kinerja. Selain itu, penelitian yang dilakukan Wiezer et al., (2011) bahwa tidak semua perubahan memberikan pengaruh negatif, perubahan yang direncanakan dan dikelola efektif memberikan pengaruh peningkatan kesejahteraan yang lebih baik, hal ini dikarenakan adanya persepsi jaminan yang dirasakan pegawai atau karyawan.

Selain itu, Westgaard dan Winkel (2011) menemukan bahwa perubahan yang didukung partisipasi aktif pegawai atau karyawan, informasi yang jelas, komunikasi dua arah, dukungan pimpinan dan organisasi, serta didorong dengan upaya tetap mempromosikan kesejahteraan pegawai, maka akan mendorong peningkatan kinerja pegawai atau karyawan yang lebih baik lagi (Schutte-Lyth et al., 2016).

\section{KESIMPULAN DAN SARAN}

Berdasarkan hasil penelitian tentang "Pengaruh Perubahan Jabatan Struktural kedalam Jabatan Fungsional Terhadap Kinerja dan Kesejahteraan Pegawai Eselon III dan IV di Lingkungan Universitas Negeri Semarang" diperoleh simpulan bahwa Change in Management dapat meningkatkan employee performance (kinerja pegawai) dan employee well-being secara signifikan (hubungan langsung). Hal ini memberikan gambaran bahwa perubahan yang dilakukan, dalam hal ini adalah perubahan jabatan struktural menjadi jabatan fungsional pada pegawai eselon III di lingkungan Universitas Negeri Semarang yang direncanakan dengan jelas (alasan, tujuan dan manfaat perubahan), diorganisasikan dengan baik, didukung, difasilitasi, dan didampingi oleh pemimpin, serta dikomunikasikan dengan baik akan meningkatkan kinerja dan kesejahteraan pegawai.

Kesejahteraan pegawai (employee well-being) yang dipromosikan dengan baik, pada saat aktivitas atau rencana perubahan akan dilakukan, saat berlangsung dan berakhir dapat meningkatkan employee performance (kinerja pegawai) secara 
signifikan. Kesejahteraan pegawai (employee well-being) berperan sebagai mediator di antara hubungan praktik manajemen perubahan (change in management) dan kinerja pegawai (employee performance). Keterbatasan pada penelitian ini adalah jumlah sampel yang relatif kecil yaitu sebesar 78 sampel, selain itu tidak adanya studi pendahuluan yang dapat memperkuat hasil penelitian yang dibangun dalam penelitian ini,

Penelitian selanjutnya disarankan untuk dapat mengeksplorasi variabel-variabel lain yang mungkin dapat memengaruhi dan mensukseskan perubahan yang direncanakan seperti peran kepemimpinan (Faupel \& Süß, 2019). Selain itu peneliti selanjutnya dapat menjadikan penelitian ini sebagai referensi untuk dapat mengetahui dampak perubahan jabatan khususnya pada institusi pendidikan tinggi atau dapat menerapkannya pada objek penelitian lainnya dengan sektor yang berbeda.

\section{IMPLIKASI MANAJERIAL}

Implikasi manajerial yang diperoleh dari penelitian ini adalah dapat memberikan gambaran terkait bagaimana perubahan yang dikelola dengan baik dan efektif, sehingga berdampak secara positif baik itu dari kinerja ataupun kesejahteraan.

\section{ACKNOWLEDMENTS}

LPPM Universitas Negeri Semarang yang mendanai penelitian ini. Dekan Fakultas Ekonomi, Universitas Negeri Semarang, Prof. Dr. Heri Yanto, MBA., Ph.D yang memberikan nasihat untuk penelitian ini. Unzilla Ainun Ulfa, S.E sebagai typists penelitian ini

\section{DAFTAR PUSTAKA}

Antara. (2013). Pengalihan Jabatan Struktural ke Jabatan Fungsional, Suatu Teaahan Penghapusan Jabatan Eselon III dan IV di Badan Kepegawaian Negara. Jurnal Kebijakan Dan Manajemen PNS, 7(1).

Bamberger, S. G., Vinding, A. L., Larsen, A., Nielsen, P., Fonager, K., Nielsen, R. N., Ryom, P., \& Omland, Ø. (2012). Impact of organisational change on mental 
health: a systematic review. Occupational Environment Medical, 69, 592-598. https://doi.org/10.1136/oemed-2011-100381

bin Shmailan, A. S. (2016). The relationship between job satisfaction, job performance and employee engagement: An explorative study. Issues in Business Management and Economics, 4(1), 1-8.

Chepkurgat, R. S., Kipkebut, D. J., \& Auka, D. O. (2019). Effect of Organisational Change on Performance in Kenyan Chartered Universities: A Sector Comparison. European Journal of Business and Management, 11(18), 77-88. https://doi.org/10.7176/EJBM

Faupel, S., \& Süß, S. (2019). The Effect of Transformational Leadership on Employees During Organizational Change-An Empirical Analysis. Journal of Change Management, 19(3), 145-166. https://doi.org/10.1080/14697017.2018.1447006

Ferdinand, A. (2014). Metode Penelitian Manajemen: Pedoman Penelitian Skripsi, Tesis dan Disertasi Ilmu Manajemen. Universitas Diponegoro.

Ghozali, I., \& Latan, H. (2015). Konsep, Teknik, Aplikasi Menggunakan Smart PLS 3.0 Untuk Penelitian Empiris. BP Undip Semarang.

Hair, J. F., Hult, G. T., Ringle, C. M., \& Sarstedt, M. (2017). A Primer on Partial Least Squares Structural Equation Modeling (PLS-SEM). In Sage (2nd Editio). SAGE.

Harahap, Y. R. (2020). PENGARUH MANAJEMEN PERUBAHAN, BUDAYA ORGANISASI DAN KUALITAS KERJA TERHADAP KINERJA PEGAWAI BADAN PENYELENGGARA JAMINAN SOSIAL (BPJS) KESEHATAN CABANG PADANG SIDEMPUAN. Jurnal Ekonomi Keuangan Dan Kebijakan Publik, 2(1), 9-16.

Harwiki, W. (2016). The Impact of Servant Leadership on Organization Culture, Organizational Commitment, Organizational Citizenship Behaviour (OCB) and Employee Performance in Women Cooperatives. Procedia - Social and Behavioral Sciences, 219(May), 283-290. https://doi.org/10.1016/j.sbspro.2016.04.032

Hayes, J., \& Hyde, P. (2016). Change Management Indicator. 
http://peterhyde.co.uk/wp-content/uploads/2013/09/The-Change-ManagementIndicator.pdf

Kahoro, C. W., \& Rugami, J. M. (2018). Change Management and Performance of Kenya Ferry Services in Mombasa County, Kenya. International Journal of $\begin{array}{llll}\text { Science } & \text { Research }\end{array}$ https://doi.org/10.21275/ART20181239

Khosa, Z. A., Rehman, Z. U., Asad, A., Bilal, M. A., Hussain, N., \& Scholars, M. P. (2015). The Impact of Organizational Change on the Employee's Performance in the Banking Sector of Pakistan. IOSR Journal of Business and ManagementVer. II, 17(3), 2319-7668. https://doi.org/10.9790/487X-17325461

Kimhi, S., Oliel, Y., M. N., O., J.C, O., O., N., U.O, E., \& Ojukwu, C. O. (2019). Change Management and Organizational Performance in Selected Manufacturing Companies in Anambra State, Nigeria. The International Journal of Social Sciences and Humanities Invention, 6(5), 5437-5445. https://doi.org/10.18535/ijsshi/v6i5.06

Kojo, A. I., Kindangen, P., \& Uhing, Y. (2019). Pengaruh Manajemen Perubahan, Budaya Organisasi Dan Keterlibatan Kerja Terhadap Kinerja Karyawan Pada Pt. Bank Sulut Go. Jurnal EMBA: Jurnal Riset Ekonomi, Manajemen, Bisnis Dan Akuntansi, 7(3), 4261-4270. https://doi.org/10.35794/emba.v7i3.25061

Menda, J. F., Tewal, B., \& Sendow, G. M. (2018). Pengaruh Manajemen Perubahan Dan Budaya Organisasi Terhadap Kinerja Pegawai Negeri Sipil (Studi Pada Rsud Bitung). Jurnal EMBA: Jurnal Riset Ekonomi, Manajemen, Bisnis Dan Akuntansi, 6(4), 2578-2587. https://doi.org/10.35794/emba.v6i4.21032

Mudeng, D. S., Tumbel, A., \& Taroreh, R. (2017). Pengaruh Perubahan Organisasi Dan Pengembangan Karir Terhadap Kinerja Karyawan Pada Kpknl Manado. Jurnal EMBA: Jurnal Riset Ekonomi, Manajemen, Bisnis Dan Akuntansi, 5(3), 28592867. https://doi.org/10.35794/emba.v5i3.17178

Pradhan, R. K., \& Jena, L. K. (2017). Employee Performance at Workplace: Conceptual Model and Empirical Validation. Businnes Perspective and Research, 
5(1), 69-85. https://doi.org/10.1177/2278533716671630

Ratnasari, S. L., Fitri, D., Zulkifli, Nasrul, H. W., \& Supardi. (2020). Analisis Manajemen Perubahan, Kepemimpinan Transformasional, Struktur Organisasi, Budaya Organisasi Dan Disiplin Kerja Terhadap Kinerja Karyawan. Jurnal Benefita, 5(2), 225-237. https://doi.org/10.22216/jbe.v5i2.5303

Santosa, P. I. (2018). Metode Penelitian Kuantitatif - Pengembangan Hipotesis dan Pengujiannya Menggunakan SmartPLS. Andi.

Schutte-Lyth, A.-M. S., Chetty, N., \& Karodia, A. M. (2016). An Investigation into the Impact of Change Management on the Wellbeing of Healthcare Workers at Rumailah Hospital in the State of Qatar. Singaporean Journal of Business Economics and Management Studies, 4(11), 1-36. https://doi.org/10.12816/0027220

Sinaga, H. G., Asmawi, M., Madhakomala, R., \& Suratman, A. (2018). Effect of Change in Management, Organizational Culture and Transformational Leadership on Employee Performance PT. AdhyaTirta Batam (PT. ATB). International Review of Management and Marketing, 8(6), 15-23. https://ideas.repec.org/a/eco/journ3/2018-06-3.html

Smollan, R. K. (2015). Causes of stress before, during and after organizational change: a qualitative study". Journal of Organizational Change Management, 28(2), 301314.

Solimun, A., Adji, R. F., \& Nurjannah. (2017). Metode Statistika Multivariat Pemodelan Persamaan Struktural (SEM) Pendekatan WarpPLS. UB Press.

Thomas, O. O. (2014). Change Management and its Effects on Organizational Performance of Nigerian Telecoms Industries: Empirical Insight from Airtel Nigeria. International Journal of Humanities Social Sciences and Education (IJHSSE), 1(11), 2349. www.arcjournals.org

Wanza, S. L., \& Nkuraru, J. K. (2016). Influence of change management on employee performance: A case of university of Eldoret, Kenya. International Journal of 
$\begin{array}{llll}\text { Business } & \text { and }\end{array}$ https://ijbssnet.com/journals/Vol_7_No_4_April_2016/22.pdf

Westgaard, R. H., \& Winkel, J. (2011). Occupational musculoskeletal and mental health: Signi fi cance of rationalization and opportunities to create sustainable production systems e A systematic review. Applied Ergonomics, 42(2), 261-296. https://doi.org/10.1016/j.apergo.2010.07.002

Wibowo. (2016). Manajemen Perubahan. Rajawali Pers.

Wiezer, N., Nielsen, K., Pahkin, K., Widerszal-Bazyl, M., Jong, T. de, Mattial-Holappa, P., \& Mockatto, Z. (2011). Exploring the link between restucturing and employee well-being (Edition 1). PSYRES consortium.

Zehra, F., \& Siddiqui, D. A. (2019). Organizational Change and Employees , Psychological Well -Being: The Mediatory Role of Resistance to Change. Available at SSRN. https://doi.org/Zehra, Fatima and Siddiqui, Danish Ahmed, Organizational Change and Employees' Psychological Well-Being: The Mediatory Role of Resistance to Change (December 28, 2019). Available at SSRN: https://ssrn.com/abstract=3510555 or http://dx.doi.org/10.2139/ssrn.3510555

Zheng, X., Zhu, W., Zhao, H., \& Zhang, C. (2015). Employee well-being in organizations: Theoretical model, scale development, and cross-cultural validation. Journal of Organizational Behavior, 36, 621-644. https://doi.org/10.1002/job 